\title{
Change of extreme rainfall indexes at Ebro River Basin
}

\author{
J. L. Valencia ${ }^{1}$, A. M. Tarquis ${ }^{2,4}$, A. Saá-Requejo ${ }^{3,4}$, and J. M. Gascó ${ }^{3}$ \\ ${ }^{1}$ Dpto. de Estadística e I.O. III, E. U. de Estadística, Universidad Complutense de Madrid, Spain \\ ${ }^{2}$ Dpto. de Matemática Aplicada, E.T.S.I.A., Universidad Politécnica de Madrid, Spain \\ ${ }^{3}$ Dpto. de Edafología, E.T.S.I.A., Universidad Politécnica de Madrid, Spain \\ ${ }^{4}$ C.E.I.G.R.A.M. - Universidad Politécnica de Madrid (U.P.M.), Spain \\ Correspondence to: J. L. Valencia (joseval@estad.ucm.es)
}

Received: 9 January 2012 - Revised: 24 April 2012 - Accepted: 27 May 2012 - Published: 5 July 2012

\begin{abstract}
Extreme rainfall events are a serious concern for regional hydrology and agriculture in the Ebro River Basin. Repeated anomalous rainfall in recent decades has had a devastating impact on this region, both socially and economically. Some studies developed in Italy and USA have shown that there is a change in seasonal patterns and an increasing frequency of extreme rainfall events, whereas other studies have pointed out that no global behaviour could be observed in monthly trends due to high climatic variability. The aim of this work is to test which of these scenarios is the case for the Ebro River Basin.

For this purpose, 14 meteorological stations were selected based on the length of the rainfall series and the climatic classification to obtain a representative untreated dataset from the river basin. Daily rainfall series from 1957 to 2002 were obtained from each meteorological station. First, classical climatic indexes were analysed with an autoregressive test to study possible trends in rainfall. The results can be explained following the evolution of the NAO and WeMO indexes, which indicate that the initial period should be subdivided in two periods (1957-1979 and 1980-2002) to assume stationarity and to analyse the rainfall distribution functions.

The general results obtained in this study for both subperiods, through the generalised Pareto distribution (GPD) parameters and the maximum expected return values, do not support the results previously obtained by other authors that affirm a positive trend in extreme rainfall indexes and point to a slight reduction indicated by others. Three extreme precipitation indexes show negative statistical significant trends. GPD-scale parameters decrease except for only one rain gauge, although this decrease is only statistically significant for two rain gauges. Another two locations show statistical significance decreased for maximum expected return values.
\end{abstract}

\section{Introduction}

Lately, several researchers have pointed out that climate change is expected to increase temperatures and lower rainfall in Mediterranean regions, simultaneously increasing the intensity of extreme rainfall events (Räisänen et al., 2004). These changes could have consequences regarding rainfall regime (Groisman et al., 2001), erosion (González-Hidalgo et al., 2007), sediment transport and water quality (O'Neal et al., 2005), soil management (Killham, 2010), and new designs in diversion ditches (Bryan et al., 2011). Climate change is expected to result in increasingly extreme and variable rainfall, in amount and timing, changing seasonal patterns and increasing the frequency of extreme weather events (Tarquis et al., 2010). Consequently, conducting a frequency analysis on the amount of rainfall in a region is one of the most common tools employed in rainfall studies. In general terms, these studies focus on the relationship between rainfall and the probability of not exceeding a fixed high quantity or determining a return period for this value (Kim et al., 2011). In general, all estimates of this probability are made by assuming stationarity in rainfall series. This assumption is not entirely realistic, especially today, when a large number of scientists claim that climate is changing dramatically (Keeling, 1973; Palmer and Räisänen, 2002; Milly et al., 2002; Cox, 2005). If the rainfall distribution has changed, it is necessary to determine whether there are specific sub-periods of time with a similar distribution. This type of treatment was not carried out in certain works that studied the evolution and probability of rainfall exceeding dangerous thresholds (Gallego et al., 2006; Rodrigo, 2010; Müller et al., 2009). These authors found a lack of stationarity in rainfall during the 1951-2002 period, especially in terms of extreme values. 
However, these authors did not try to find different distribution functions for those years.

Generally, most research focuses on the calculation of trends or the determination of the probability distribution that follows the rainfall in a station. One of the few exceptions of this methodology can be found in the work of Gallego et al. (2006). These researchers examined the data of 35 rainfall stations in Spain between 1958 and 1997 using the Kendall test and concluded that there was an increasing trend in the number of days with light rainfall in every season. However, they also observed that the number of days with moderate, intense and very intense rainfall was diminishing, especially in spring and winter. This same result was found by Rodrigo (2010), who adjusted daily precipitation at a gamma distribution from 1951 to 2002 and showed the evolution of the scale and shape parameters.

Some teleconnection patterns, such as the Western Mediterranean Oscillation (WeMO) and the North Atlantic Oscillation (NAO), are often associated with variations in rainfall in this part of the world (Wang, 2002; Martin Vide et al., 2008; Gonzalez-Hidalgo et al., 2009) and could explain the rainfall pattern at the Ebro basin. We will use these indexes later to study the relationship between WeMO and NAO with the rainfall variation trend over time.

Realising the complex and important consequences of an increasing frequency of extreme rainfall events at the Ebro River Basin (Valencia, 2007), our aim is to study the evolution of rainfall events at this site statistically, with emphasis on the occurrence and intensity of extreme events. To achieve this, a recent methodology based on the work of other authors (Coles, 2001; Toreti et al., 2010; Bodini and Cossu, 2010) will be applied to estimate the probability distributions following periods of torrential rains in this area. The novelty is combining stationarity analysis with a GPD.

\section{Methodology}

\subsection{Rainfall climatic indexes}

Some generalised indexes reported by the World Climate Research Programme (Peterson et al., 2001) are calculated. These indexes have been applied by other authors, such as Brunetti et al. (2004) and Bodini and Cossu (2010). The notation used in this work is as follows:

RF: Relative Frequency of rainy days ( $\geq 1 \mathrm{~mm}$ )

TP: Total annual Precipitation

MEAN: MEAN precipitation in a rain day

MAX: daily MAXimum precipitation

MAX5: MAXimum 5-day precipitation total

P95: Percentile of order 0.95 based on wet days
RF10: Relative Frequency of days with precipitation $\geq 10 \mathrm{~mm}$

MAXDRY: MAXimum number of consecutive DRY days

Extreme events are defined as daily totals above the 95th percentile calculated from wet days at each rainfall gauge from 1957 to 2002. Their values are described at the annual and seasonal scales. These extremes indexes are as follows:

TEX: annual accumulaTion of EXtreme rainfall events;

PREX: PRoportion of annual accumulation due to EXtreme events

M_EX: Mean of EXtreme events

\subsection{Trend analysis}

In the Mediterranean area, the existence of a trend in precipitation, particularly in heavy rainfall, is not yet clear. Linear trends were checked by the linear regression model with autocorrelated disturbances, such as with the Yule-Walker method described in Harvey (1990):

$$
\begin{aligned}
& y_{i, t}^{(s)}=\beta_{i}^{(s)} t+v_{i, t}^{(s)} \\
& v_{i, t}^{(s)}=\varepsilon_{i, t}^{(s)}+\phi_{i, 1}^{(s)} v_{i, t-1}^{s}+\phi_{i, 2}^{(s)} v_{i, t-2}^{s}+\ldots+\phi_{i, k}^{(s)} v_{i, t-k}^{s}
\end{aligned}
$$

In this equation, $y_{i, t}^{(s)}$ represents the rainfall index $i$ at moment $t$ at station $s ; \beta_{i}{ }^{(s)}$ is the trend of this index at station $s ; \varepsilon_{i, t}^{(s)}$ is a variable that is normally and independently distributed with a mean of 0 and a standard deviation of $\sigma_{i}^{(s)}$, and $\phi_{i, 1}^{(s)}$ are the autoregressive parameters. One index has a trend if the $\beta_{i}{ }^{(s)}$ parameters are statistically significant for station $s$.

According to Harvey (1990), due to the high interannual variability, a sensitivity analysis of the influence of extreme high values has been carried out. The trends were considered significant if they persisted after removing the extreme values.

\subsection{Distribution functions}

The gamma distribution family is usually used to fit the rainfall at one place. However, this distribution does not fit the queues properly, often producing higher values than expected for rainfall distributions. The problem is that this error can be crucial for obtaining the return times for a given amount. To resolve this problem, Coles (2001) proposed using the generalised Pareto distribution (GPD) for fit values above a given threshold. The function of this distribution is

$$
F(x)=\left\{\begin{array}{r}
1-\left(1+\frac{\xi(x-u)}{\sigma_{\mathrm{GPD}}}\right)^{-1 / \xi} \xi \neq 0 \\
1-e^{-\left(\frac{x-u}{\sigma_{\mathrm{GPD}}}\right)} \quad \xi=0 \\
\text { with }\left(1+\frac{\xi(x-\mu)}{\sigma_{\mathrm{GPD}}}>0\right)
\end{array}\right.
$$


where $u$ is the threshold parameter, $\sigma_{\mathrm{GPD}}$ is a scale parameter and $\xi$ is a shape parameter. The characterisation and properties of GPD were introduced by Pickands (1975).

The principal features of this distribution are that it reflects higher tails better than others, such as the exponential and gamma distributions, where $\xi>0$ (although it is visually similar to these), and $x$ has no upper limit.

However, if the daily rainfall is distributed like a GPD, then the daily maximum precipitation at a period of time must be fit to a generalised extreme values (GEV) distribution, with the same shape parameter of GPD. Its distribution function is

$$
\begin{aligned}
& F(x)=\left\{\begin{array}{cc}
1-e^{-\left(1+\frac{\xi(x-\mu)}{\sigma_{\mathrm{GEV}}}\right)^{-\frac{1}{\xi}}} & \xi \neq 0 \\
1-e^{-e^{-\left(\frac{(x-\mu)}{\sigma_{\mathrm{GEV}}}\right)}} & \xi=0
\end{array}\right. \\
& \text { with }\left(1+\frac{\xi(x-\mu)}{\sigma_{\mathrm{GEV}}}>0\right) \text {. }
\end{aligned}
$$

If $\xi \neq 0$, it must verify the condition $1+\frac{\xi(x-\mu)}{\sigma_{\mathrm{GEV}}}>0$

where $\xi$ is the same shape parameter as for the GPD distribution, and $\sigma_{\mathrm{GEV}}>0$ and $\mu$ are the scale and location parameters, respectively. This scale parameter $\left(\sigma_{\mathrm{GEV}}\right)$ is different from the GPD scale parameter $\left(\sigma_{\mathrm{GPD}}\right)$, although there is a relation between them:

$\sigma_{\mathrm{GPD}}=\sigma_{\mathrm{GEV}}+\varepsilon(u-\mu)$.

It is also interesting to obtain the distribution parameters to calculate the expected return time $(m)$ for a given level $x_{m}$ of rainfall in a day. Replacing these parameters in the following formula (Coles, 2001) gives us the following estimation:

$m=\frac{\left[1+\xi\left(\frac{x_{m}-u}{\sigma_{\mathrm{GEV}}}\right)\right]^{\frac{1}{\xi}}}{p_{u}}$

where $p u=\operatorname{Pr}(X>u)$. Rearranging the terms, the maximum expected return level $(x \mathrm{~m})$ can be estimated with the following equation:

$x_{m}= \begin{cases}u+\frac{\sigma_{\mathrm{GEV}}}{\varepsilon}\left(\left(m p_{u}\right)^{\xi}-1\right) & \xi \neq 0 \\ u+\sigma_{\mathrm{GEV}} \log \left(m p_{u}\right) & \xi=0\end{cases}$

where $m$ is the number of considered days (time period set). In general, $m$ usually gives return levels on an annual scale. To evaluate the confidence intervals of these parameters, the classical delta method (Oehlert, 1992) has been used.

It is desirable to check over the model after the results have been obtained. The principal options are the following:

1. P-P plot: If $y_{(1)} \leq y_{(2)} \leq \ldots y_{(k)}$ (with $y_{i}=x_{i}-u$ ) are the excesses observed above a threshold $u$, the graph represents the empirical distribution function against the expected, i.e. $\left\{\left(\frac{i}{k+1}\right), 1-\left(1+\frac{\hat{\xi} y_{(i)}}{\hat{\sigma}}\right)^{-1 / \xi}\right\}$. If the data are correctly adjusted, the plot is a straight line (see Cleveland, 1985, for more details).

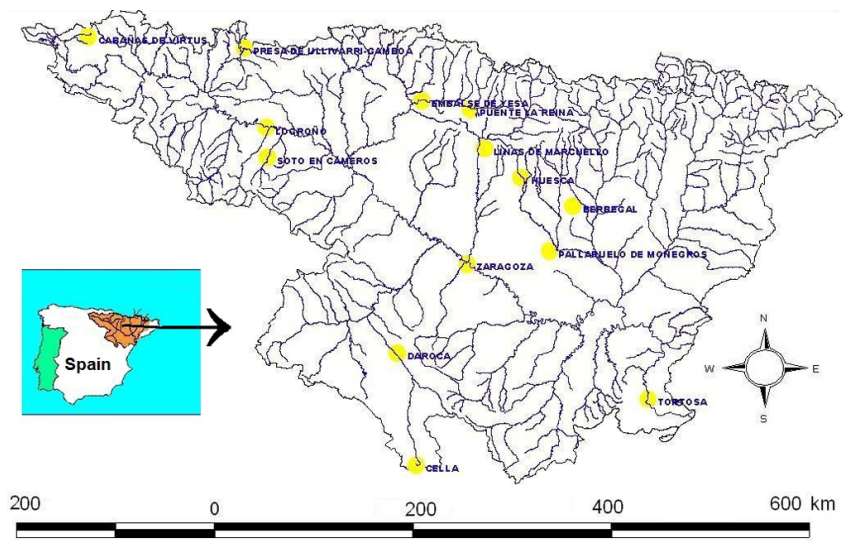

Fig. 1. Distribution of 14 rainfall gauges in the Ebro River Basin (Spain).

2. q-q plot: This graph represents the theoretical quantile against the observed quantile, i.e. $\left\{\left(u+\frac{\hat{\sigma}}{\hat{\xi}}\left(\left(1-\frac{i}{k+1}\right)^{-\hat{\xi}}-1\right)\right), y_{(i)}\right\}$. Again, if the model fits the data well, the plot must be a straight line (see Cleveland, 1985, for more details).

3. We can generate a random sample of the GPD $(\hat{\xi}, \hat{\sigma})$ and test whether it comes from the same probability distribution of our observed data using Kuiper's and the Kolmogorov-Smirnov tests (Hollander and Wolfe, 1999).

\section{Data and site study}

The Ebro basin is one of the major Spanish depressions. This basin has a general pail-shaped layout, where the mountain ranges define the following peripheral areas: the Pyrenees and Basque-Cantabrian mountains in the north, the Iberian System in the south and the Catalan Mountains coastal chain in the east. These three mountains regions leave between them a more depressed flat area named the Ebro Depression. This area is drained by the Ebro River, which runs in a northwest to southeast direction between the Pyrenees and the Iberian System. On the left of the main axis is a river basin area of approximately $50000 \mathrm{~km}^{2}$, and on its right is an area of approximately $30000 \mathrm{~km}^{2}$. For further details, see Valencia (2007) and references therein.

The precipitation in the region is scarce and is mainly concentrated in the spring and autumn seasons. Summer and winter generally register the minimum rainfall. The precipitation, in addition to its scarcity, shows a strong interannual and inter-monthly irregularity with long periods of no precipitation. Some authors have recently performed a more rigorous analysis on the evolution of rainfall in this zone. Gonzalez-Hidalgo et al. (2009) studied the monthly precipitation trends in the Mediterranean fringe of the Iberian 
Table 1. Mean of the rainfall climatic indexes at the selected stations for 1957-2002 period. Relative frequency of rainy days (RF), total annual precipitation (TP), mean precipitation in a rain day (MEAN), daily maximum (MAX), maximum 5-day precipitation total (MAX5), percentile of order 0.95 based on wet days (P95), relative frequency of days with precipitation $\geq 10$ mm (RF10), maximum number of consecutive dry days (MAXDRY), annual accumulation of rainfall extremes (TEX), proportion of annual accumulation due to extreme events (PREX), mean of extreme events (M_EX).

\begin{tabular}{|c|c|c|c|c|c|c|c|c|c|c|c|c|}
\hline RAIN GAUGES & Code & $\mathrm{RF}$ & $\mathrm{TP}$ & MEAN & MAX & MAX5 & P95 & RF10 & MAX DRY & TEX & PR_EX & M_EX \\
\hline CABAÑAS DE VIRTUS & A1 & 31.1 & 1078.1 & 9.4 & 57.0 & 127.6 & 29.9 & 9.3 & 20.0 & 246.8 & 21.3 & 41.5 \\
\hline PRESA ULLIVARRI-GAMBOA & $\mathrm{A} 2$ & 31.0 & 927.4 & 8.1 & 48.2 & 99.9 & 26.4 & 8.0 & 20.0 & 204.7 & 21.6 & 36.8 \\
\hline EMBALSE DE YESA & A3 & 34.7 & 791.5 & 6.4 & 33.9 & 70.9 & 17.8 & 5.7 & 16.9 & 161.6 & 19.7 & 23.9 \\
\hline LINAS DE MARCUELLO & A5 & 26.7 & 1002 & 10.2 & 55.0 & 107.8 & 30.0 & 9.7 & 29.1 & 201.8 & 19.3 & 40.2 \\
\hline HUESCA & A6 & 19.2 & 582.4 & 8.1 & 49.3 & 78.5 & 26.1 & 5.1 & 29.2 & 130.8 & 21.5 & 37.4 \\
\hline BERBEGAL & A7 & 14.7 & 480.5 & 9.0 & 48.1 & 70.6 & 27.8 & 4.1 & 41.7 & 104.1 & 20.6 & 35.9 \\
\hline DAROCA & B4 & 18.9 & 423.0 & 5.9 & 35.0 & 54.1 & 18.9 & 2.9 & 28.1 & 94.8 & 21.2 & 27.0 \\
\hline CELLA & B5 & 14.8 & 386.3 & 7.1 & 40.0 & 61.5 & 22.6 & 3.0 & 36.5 & 91.2 & 21.9 & 31.7 \\
\hline ZARAGOZA & $\mathrm{B} 2$ & 14.2 & 345.9 & 6.3 & 39.1 & 58.3 & 21.7 & 2.4 & 33.8 & 85.6 & 22.3 & 30.3 \\
\hline PALLARUELO DE MONEGROS & A8 & 13.9 & 397.1 & 7.6 & 43.1 & 64.5 & 25.1 & 3.3 & 37.3 & 91.6 & 21.2 & 32.4 \\
\hline TORTOSA & B6 & 14.1 & 554.8 & 10.4 & 72.6 & 121.2 & 39.5 & 4.2 & 32.6 & 156.3 & 25.6 & 57.3 \\
\hline
\end{tabular}

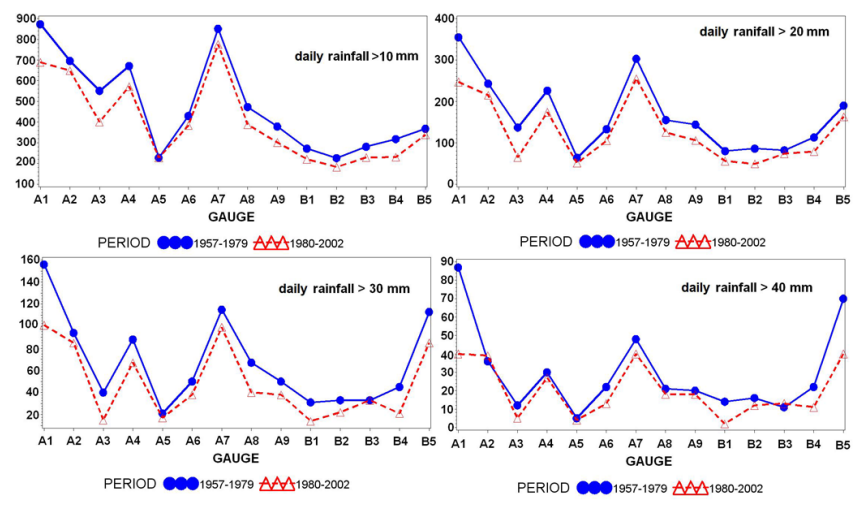

Fig. 2. Number of daily rainfall events exceeding 10, 20, 30 and $40 \mathrm{~mm}$ of rainfall at each station for two consecutive periods.

Peninsula from 1951 to 2000 . Their results demonstrated that no global behaviour could be observed in monthly trends, except in March, which showed a generally negative trend. They suggested that precipitation studies based on a monthly scale might obscure the intrinsic variability that is required to understand the complex rainfall pattern in the region. LopezBustings et al. (2008) presented a significant decrease in winter precipitation in the western part of the Ebro River Basin and none in the eastern part. They concluded that the cause of this pattern is a high frequency of high pressure over Iberia, which they proved using teleconnection indexes. In contrast, Valencia et al. (2010), using multifractal analysis, showed that there are no rainfall variations at the Ebro River Basin.

Our data consist of 14 data series from several meteorological stations located at different sites in the Ebro River Basin using daily rainfall data from 1957-2002. Figure 1 shows the distribution of the rainfall stations in the catchment. These

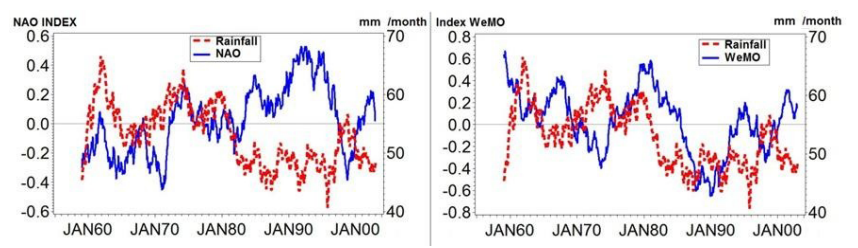

Fig. 3. Mean month rainfall in our 14 gauges of Ebro River Basin and NAO index (a) and WeMO Index (b). Series are smoothed of the last 36 month.

time series were provided, among other data, by the Confederación Hidrográfica del Ebro over a period of 46 yr (19572002). One station, located close to the origin of the river (Cabañas de Virtus), has an approximated oceanic climate. Another station, located close to the end of the river (Tortosa), has a clear Mediterranean climate. Some stations, such as Cella and Daroca, have a continental climate, whereas others, such as Zaragoza and Pallaruelo de Monegros, are in an arid area. In contrast, some stations close to the Pyrenees belong to a humid regimen, such as Linas de Marcuello, Puente la Reina, Presa de Ullivarri Gamboa and Embalse de Yesa. These selected stations are a fully representative sample of the different climate types found at the river gauges.

The code column is useful to better understand some of the graphs and tables shown later. The letter A in this code indicates that the station is on the left bank of the river (north); the letter B means that the station is on the right (south). The number of the code grows when the stations are nearer to the mouth (east). 
Table 2. Significant trends ( $p<0.05)$ of several indexes at the annual scale: relative frequency of rainy days $(\mathrm{RF})$, total annual precipitation (TP), mean precipitation in a rain day (MEAN), daily maximum (MAX), maximum 5-day precipitation total (MAX5), percentile of order 0.95 based on wet days (P95), relative frequency of days with precipitation $\geq 10 \mathrm{~mm}$ (RF10), maximum number of consecutive dry days (MAXDRY), annual accumulation of rainfall extremes (TEX), proportion of annual accumulation due to extreme events (PREX), mean of extreme events (M_EX).

\begin{tabular}{lrrrrrrrrrrr}
\hline RAIN & RF & TP & MEAN & MAX & MAX5 & P95 & RF10 & MAXDRY & TEX & PEX & M_EX \\
GAUGES & & & & & & & & & & & \\
\hline A1 & - & - & -0.090 & - & - & - & - & - & - & - & - \\
A2 & -0.216 & - & - & - & - & - & - & - & - & - & - \\
A3 & - & - & -0.102 & - & -0.872 & -0.301 & -0.071 & - & -6.26 & - & - \\
A4 & - & - & - & - & - & - & - & - & - & - & - \\
A5 & - & - & - & - & - & - & - & - & - & - & - \\
A6 & - & -4.21 & - & - & - & - & - & - & -2.62 & - & - \\
A7 & - & - & -0.078 & - & - & - & -0.039 & - & - & - & - \\
A8 & - & -3.45 & -0.062 & - & - & -0.230 & -0.047 & - & - & - & - \\
B1 & - & - & - & - & - & - & - & - & - & - & - \\
B2 & -0.132 & & - & - & - & - & - & - & - & - & - \\
B3 & - & & -0.031 & - & - & - & - & - & - & - & - \\
B4 & - & - & - & -0.354 & - & - & - & - & - & - & -0.196 \\
B5 & - & - & -0.042 & - & - & - & - & - & - & - & - \\
B6 & - & & - & - & - & - & - & - & - & - & - \\
\hline
\end{tabular}

\section{Results and discussion}

\subsection{Trends of rainfall climatic indexes}

The averages of the classical rainfall climatic indexes for each station are shown in Table 1. The highest total precipitation amounts are found for the Pyrenees at the north of the Ebro River Basin. The Embalse de Yesa station shows the highest RF (127 days $=34.7 \%)$, whereas Tortosa, in the east, shows only 51 days $(14.1 \%)$, indicating the maximum precipitation intensity at this station. In general, there is a direct relationship between the RF, the MEAN and the amount of rainfall caused by value extremes (M_EX). The only exception is Tortosa, at the mouth of the river near the Mediterranean Sea, which has a greater proportion of rainfall due to extreme values. Looking at Tortosa's ("B6") values, we observe that MEX (57.3) is much higher (45\%) than P95_1 (39.5\%). Meanwhile, Berbegal (A7) and Pallaruelo de Monegros (A8) show an MEX value $29 \%$ higher than that of P95. Embalse de Yesa (A3) presents a unique situation, having the lowest P95 and the highest proportion of wet days (the lowest MAXDRY value).

To test the effects of climate change in this area, we study the trends for all measurements at each rainfall gauge. All precipitation indexes show negative trends at the yearly scale, but only a few indexes are statistically significant at a $5 \%$ level, as can be observed in Table 2. It is remarkable that no station presented a clear trend in the maximum number of consecutive dry days and in proportion to the annual accumulation due to extreme events. Moreover, except for Daroca, there are no statistically significant trends with respect to the average rainfall caused by extreme values. For a decrease in the annual accumulation of rainfall extremes, only two rain gauges have a significant value. The importance of the extremes has not undergone any significant change, contrary to what the climate change models predict. However, we did detect a decreasing trend in average rainfall at six stations, especially at those close to the Pyrenees and the Pallaruelo de Monegros.

This result agrees with Toreti et al. (2010) for the Mediterranean area, where they found eight stations from a total of twenty presenting a negative trend. Bodini and Cossu (2010) also observed a decreasing trend, especially in winter, at eighteen stations in Sardinia (Italy). Barrera et al. (2006) studied the trend of rainfall in Barcelona using a Monte Carlo technique, and they concluded that the number of catastrophic flash floods has diminished in Barcelona from 1850 2000.

It can be appreciated (Table 2) that RF, TP and MEAN show a slight reduction that could be constant through time or at an abrupt step. If we subdivide this period in two parts (1957-1979 and 1980-2002), we observe that there is a higher frequency on days with more than $10,20,30$, and $30 \mathrm{~mm}$ in the first period than in the second at all stations (see Fig. 2). From Fig. 3, discontinuity for the mean rainfall in Ebro River is perceived around the middle of this period. That is consistent with other authors for the Mediterranean area (Rodriguez et al., 1999; Ramos, 2001). Although not presented in this work, we have checked the discontinuity through the methodology of Zurbenko et al. (1996). On the other hand, Lopez Bustin et al. (2008) suggest that the teleconnection indexes have an intense relationship with the rainfall in Spain, because their trends are consistent with changes 
Table 3. Correlation between the 3-yr moving average series of rainfall in Ebro River Basin with NAO and WeMO indexes for two different periods.

\begin{tabular}{lrr}
\hline Correlation with rainfall & Period: $1957-1979$ & Period: $1980-2002$ \\
\hline NAO index & $0.356(\mathrm{p}$-value $<0.0001)$ & $-0.464(\mathrm{p}$-value $<0.0001)$ \\
WMO index & $-0.645(\mathrm{p}$-value $<0.0001)$ & $0.355(\mathrm{p}$-value $<0.0001)$ \\
\hline
\end{tabular}
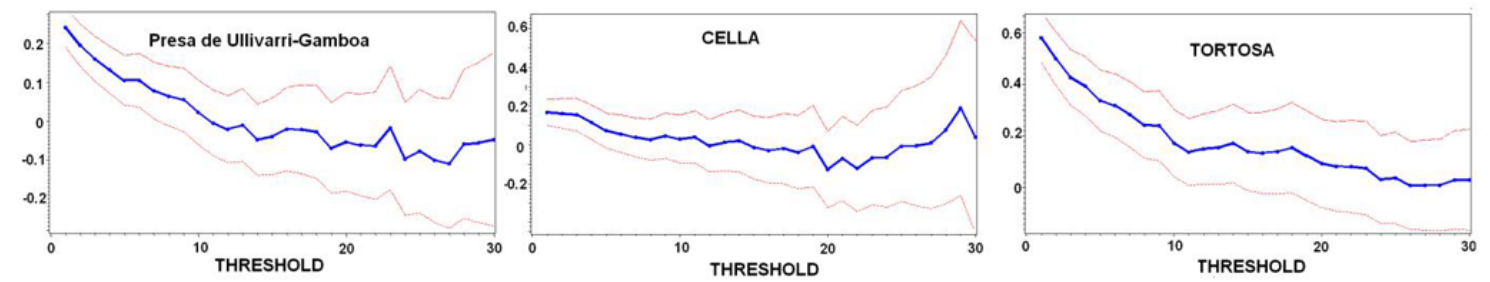

FIRST PERIOD: $1957-1979$
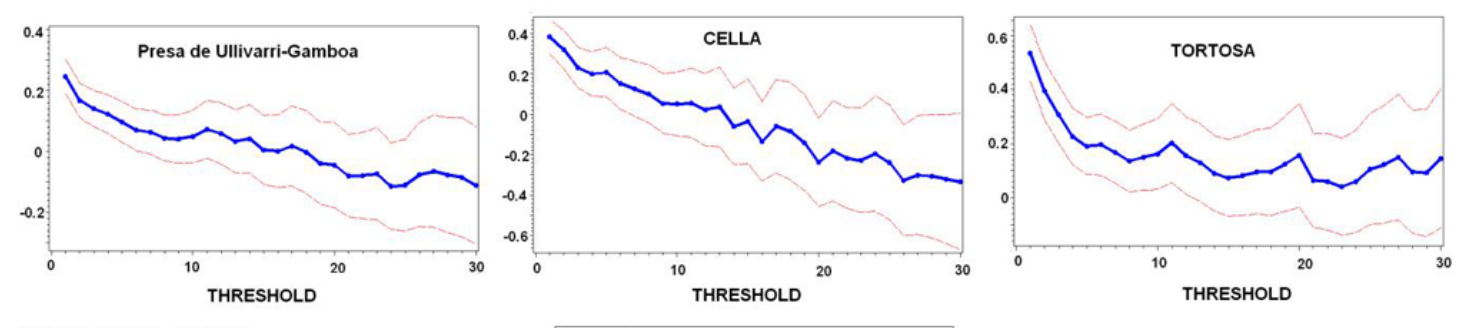

SECOND PERIOD: 1980-2002

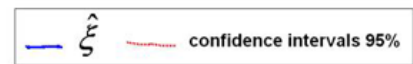

Fig. 4. Plot of estimated GPD parameter $(\xi)$ like function of threshold $u$, at annual scale for the 1957-1979 (top) and 1980-2002 (bottom) periods. Red lines represent the $95 \%$ of confidence interval. According to the theory, linearity would be expected from a $\hat{u}$ value.

in the frequency of circulation patterns. For this reason, we evaluate if there existed any significant change in the pattern of these indexes at the second half of the last century, and we compared it with our data series. We used the anomalies in the differences of the atmospheric pressure at two distant points, particularly the NAO teleconnection index and the WeMo index, to study their relations within these two periods. For example, the NAO index had a negative correlation, causing a decrease in rainfall in the second period (see Fig. 3), whereas during the first period, it had a positive correlation with rainfall in the Ebro River Basin until the late 1970s, when this correlation changed the sign. We calculated the Kendall correlations between the total rainfall at our 14 stations and the two indexes following the work of Lopez Bustins et al. (2008). The results, summarised in Table 3 , confirm that the changing relationship occurred around the last years of the 1970s.

\subsection{Rainfall distributions}

Given the previous results, we decided to adjust the precipitation to a GPD separately for each sub-period (19571979 and 1980-2002) under the hypothesis of stationarity for each time interval. We examined the scale $(\sigma)$ and shape $(\xi)$ parameters and checked their differences between the two periods considering $95 \%$ confidence intervals. An initial problem was to decide the threshold value, as the stabilisation requires that, from a value $u$, the shape and the scale parameter should vary linearly. Figure 4 shows the patterns found for both periods at three representative gauges. The plots of GPD-estimated parameter $\xi$ against the threshold $u$ suggest that the GPD model is adequate for $u \geq 10$.

Table 4 shows the parameters for all the stations for both periods. If the confidence interval contains a value of 0 , we can assume that the shape parameter is 0 and that the GPD became an exponential function distribution (see Eq. 2 and Coles, 2001).

In general, the estimated scale parameter decreases at all gauges except Cella, although this reduction is statistically significant at $95 \%$ only in the north of the basin, near the Pyrenees in Cabañas de Virtus (A1) and Embalse de Yesa (A3). Tortosa (B6), near the Mediterranean Sea, has the highest scale parameter value (15.2) and the highest absolute reduction in the second period (from 15.2 to 12.2); however, it has an excessively wide confidence interval, so it did not yield a statistically significant difference. Surprisingly, the same regularity in the trends of the shape parameters is not apparent; some of them increase, whereas others decrease, and none show statistically significant differences. 
Table 4. GPD estimated parameters $\hat{\sigma}$ and $\hat{\xi}$ (optimum scale and shape parameters respectively) for each period with threshold=10. Confidence intervals are based on the delta method.

\begin{tabular}{|c|c|c|c|c|c|c|c|c|}
\hline \multirow{2}{*}{ GAUGE } & \multicolumn{4}{|c|}{ Period: 1957-1979 } & \multicolumn{4}{|c|}{ Period: 1980-2002 } \\
\hline & $\hat{\sigma}$ & $95 \% \mathrm{CI}(\hat{\sigma})$ & $\hat{\xi}$ & $95 \% \mathrm{CI}(\hat{\xi})$ & $\hat{\sigma}$ & $95 \% \mathrm{CI}(\hat{\sigma})$ & $\hat{\xi}$ & $95 \%$ CI $(\hat{\xi})$ \\
\hline A1 & 11.3 & $(10.2,12.4)$ & 0.088 & $(0.012,0.164)$ & 9.3 & $(8.6,10.0)$ & 0.071 & $(-0.016,0.158)$ \\
\hline $\mathrm{A} 2$ & 9.4 & $(8.7,10.1)$ & 0.023 & $(-0.060,0.106)$ & 9.2 & $(8.5,9.9)$ & 0.050 & $(-0.036,0.136)$ \\
\hline A3 & 6.8 & $(6.0,7.6)$ & 0.113 & $(0.024,0.202)$ & 5.2 & $(4.6,5.8)$ & 0.086 & $(-0.023,0.195)$ \\
\hline A4 & 8.8 & $(7.8,9.8)$ & 0.086 & $(0.001,0.171)$ & 7.9 & $(6.9,8.9)$ & 0.124 & $(0.029,0.219)$ \\
\hline A5 & 9.5 & $(8.8,10.2)$ & 0.068 & $(-0.005,0.141)$ & 9.2 & $(8.3,10.1)$ & 0.074 & $(0.002,0.146)$ \\
\hline A6 & 8.7 & $(7.5,9.9)$ & 0.120 & $(0.022,0.218)$ & 7.8 & $(6.6,9.0)$ & 0.156 & $(0.043,0.269)$ \\
\hline A7 & 10.7 & $(9.6,11.8)$ & 0.048 & $(-0.044,0.140)$ & 9.8 & $(8.6,11.0)$ & 0.051 & $(-0.073,0.175)$ \\
\hline A8 & 9.6 & $(8.5 .10 .7)$ & 0.081 & $(-0.037,0.199)$ & 8.3 & $(7.1,9.5)$ & 0.114 & $(-0.025,0.253)$ \\
\hline B1 & 7.6 & $(6.6,8.6)$ & 0.026( & $(-0.121,0.173)$ & 5.8 & $(4.6,7.0)$ & 0.177 & $(0.014,0.340)$ \\
\hline $\mathrm{B} 2$ & 8.5 & $(7.6,9.4)$ & 0.075 & $(-0.026,0.176)$ & 7.9 & $(7.1,8.7)$ & 0.075 & $(-0.031,0.181)$ \\
\hline B3 & 9.9 & $(8.5,11.3)$ & 0.052 & $(-0.095,0.199)$ & 7.5 & $(5.8,9.2)$ & 0.183 & $(0.005,0.362)$ \\
\hline B4 & 9.0 & $(7.9,10.1)$ & 0.022 & $(-0.097,0.141)$ & 7.3 & $(6.3,8.3)$ & -0.010 & $(-0.166,0.146)$ \\
\hline B5 & 9.1 & $(8.0,10.2)$ & 0.031 & $(-0.093,0.155)$ & 9.4 & $(8.1,10.7)$ & 0.051 & $(-0.106,0.208)$ \\
\hline B6 & 15.2 & $(12.7,17.7)$ & 0.173 & $(0.043,0.303)$ & 12.2 & $(10.2,14.2)$ & 0.162 & $(0.031,0.293)$ \\
\hline
\end{tabular}
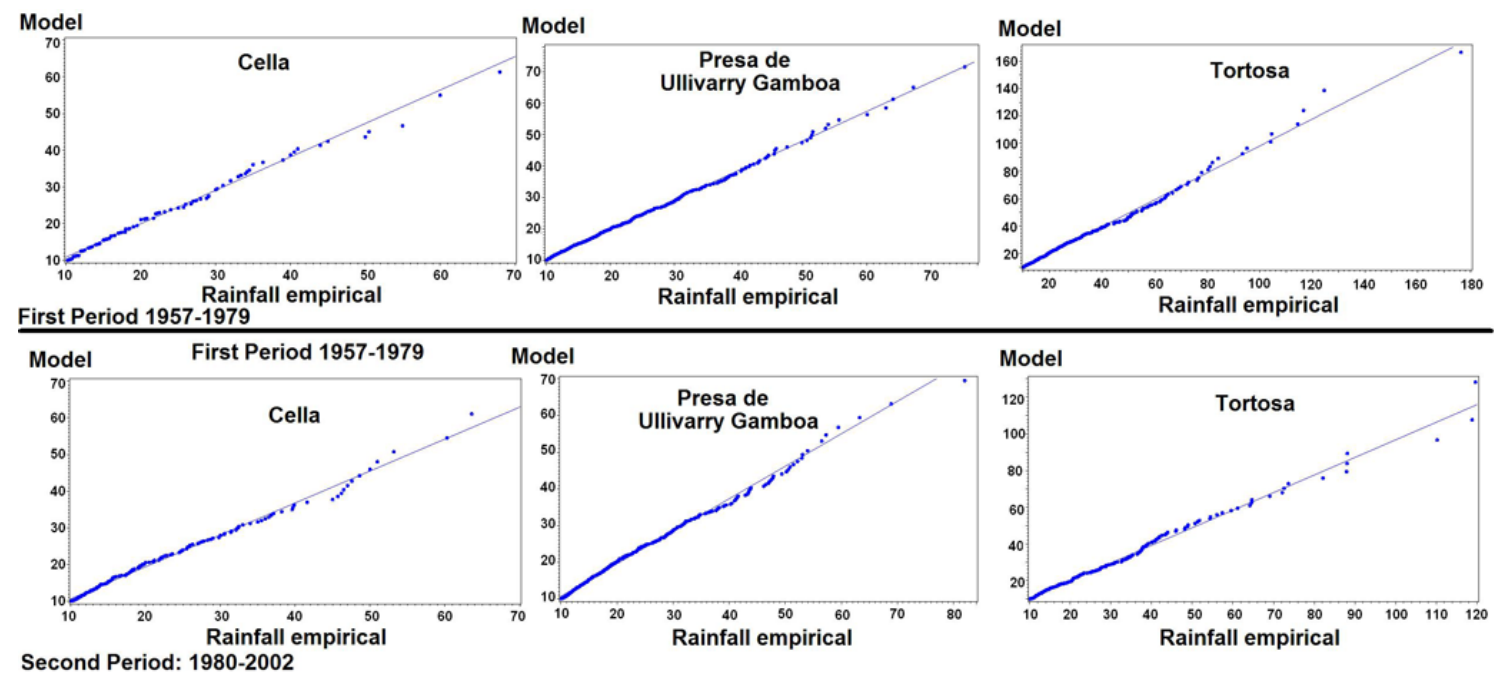

Fig. 5. The q-q plots showing model departures at Cella, Presa de Ullibarri-Gamboa and Tortosa. At the top, the first period (1957-1979) and at the bottom, the second one (1980-2002).

Combining the results obtained for both parameters, we can conclude that there is a slightly significant reduction of extreme values in our basin in the regions with more precipitation, most likely near the Mediterranean Sea, but the results are not conclusive.

Diagnostic q-q plots generally suggest a good fit, as Fig. 5 shows for 3 representative gauges. The goodness-of-fit pvalue of the GPD parameters $(\hat{\varepsilon}, \hat{\sigma})$ is presented in Table 5 . All stations fit well according to the Kolmogorov-Smirnov test criteria. Tortosa (B6) was more difficult to fit graphically, and Presa de Ullibarri-Gamboa (A2) and Cella (B5) show low values for Kuiper's test. The P-P plots (not shown) are well adjusted at all gauges.

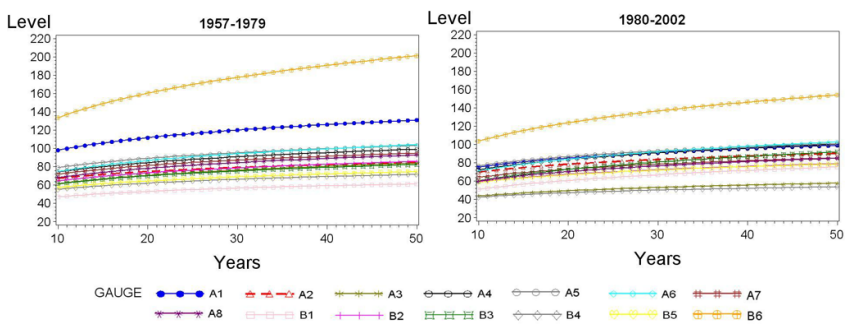

Fig. 6. Expected maximum value of rainfall daily return level (mm) versus number of years return in two consecutive periods (19571979, 1980-2002). Each station is represented by its code. 
Table 5. P-values from Kolmogorov-Smirnov (KS) and Kuiper's tests of goodness of fit to the GPD distribution for each period.

\begin{tabular}{lrrrrr}
\hline \multirow{2}{*}{ Station } & \multicolumn{2}{c}{ Period: $1957-1979$} & & \multicolumn{2}{c}{ Period: 1980-2002 } \\
\cline { 2 - 3 } \cline { 5 - 6 } & P-value KS & P-value Kuiper & & P-value KS & P-value Kuiper \\
\hline A1 & 0.4857 & 0.29979 & & 0.2854 & 0.14691 \\
A2 & 0.2302 & 0.21299 & & 0.2816 & 0.05204 \\
A3 & 0.6598 & 0.31915 & & 0.3316 & 0.19457 \\
A4 & 0.5053 & 0.36434 & & 0.5453 & 0.46754 \\
A5 & 0.6472 & 0.28375 & & 0.4195 & 0.17280 \\
A6 & 0.6397 & 0.59054 & & 0.5177 & 0.23334 \\
A7 & 0.2248 & 0.06483 & & 0.3354 & 0.07837 \\
A8 & 0.5088 & 0.16260 & & 0.8691 & 0.63839 \\
B1 & 0.3905 & 0.29381 & & 0.6550 & 0.80643 \\
B2 & 0.6441 & 0.29897 & & 0.5271 & 0.15720 \\
B3 & 0.2892 & 0.18560 & & 0.4170 & 0.43832 \\
B4 & 0.3445 & 0.10602 & & 0.4918 & 0.69362 \\
B5 & 0.2946 & 0.01719 & & 0.1802 & 0.09522 \\
B6 & 0.7040 & 0.71156 & & 0.3460 & 0.12419 \\
\hline
\end{tabular}

Table 6. Estimated return rainfall levels $\left(\mathrm{mm} \mathrm{day}^{-1}\right)$ and their $95 \%$ confidence intervals for selected return times in years, by delta method.

\begin{tabular}{|c|c|c|c|c|c|c|c|c|c|c|}
\hline \multirow{2}{*}{ Gauge } & \multicolumn{5}{|c|}{ TIME (Period: 1957-1979) } & \multicolumn{5}{|c|}{ TIME (Period: 1980-2002) } \\
\hline & $10 \mathrm{yr}$ & $20 \mathrm{yr}$ & $30 \mathrm{yr}$ & $40 \mathrm{yr}$ & $50 \mathrm{yr}$ & $10 \mathrm{yr}$ & $20 \mathrm{yr}$ & $30 \mathrm{yr}$ & $40 \mathrm{yr}$ & $50 \mathrm{yr}$ \\
\hline \multirow[b]{2}{*}{ A1 } & 98.1 & 111.8 & 120.1 & 126.2 & 131.1 & 63.0 & 69.5 & 73.2 & 75.9 & 78.0 \\
\hline & $(76.9,119.4)$ & $(83.7,139.8)$ & $(87.5,152.7)$ & $(90.1,162.3)$ & $(92,170.1)$ & $(56,70.1)$ & $(61.7,77.3)$ & $(65,81.5)$ & $(67.3,84.5)$ & $(69.2,86.8)$ \\
\hline \multirow{2}{*}{$\mathrm{A} 2$} & 63.7 & 70.2 & 74.0 & 76.7 & 78.8 & 61.9 & 68.3 & 72.0 & 74.7 & 76.7 \\
\hline & $(56.8,70.6)$ & $(62.6,77.8)$ & $(66,82.1)$ & $(68.4,85.1)$ & $(70.2,87.4)$ & $(54.9,68.9)$ & $(60.5,76.1)$ & $(63.8,80.2)$ & $(66.1,83.2)$ & $(67.9,85.5)$ \\
\hline \multirow{2}{*}{ A3 } & 61.6 & 70.7 & 76.42 & 80.5 & 83.9 & 36.8 & 40.4 & 42.5 & 44.0 & 45.2 \\
\hline & $(49.6,73.5)$ & $(55.2,86.2)$ & $(58.3,94.4)$ & $(60.5,100.6)$ & $(62.2,105.6)$ & $(30.4,43.3)$ & $(33.3,47.6)$ & $(34.9,50.2)$ & $(36.1,52)$ & $(37,53.4)$ \\
\hline \multirow{2}{*}{ A4 } & 74.4 & 84.6 & 90.9 & 95.5 & 99.1 & 72.5 & 83.9 & 91.0 & 96.2 & 100.4 \\
\hline & $(59.8,89)$ & $(65.5,103.7)$ & $(68.7,113.1)$ & $(70.9,120.1)$ & $(72.5,125.8)$ & $(54.6,90.5)$ & $(59.5,108.3)$ & $(62,119.9)$ & $(63.7,128.8)$ & $(64.8,136)$ \\
\hline \multirow{2}{*}{ A5 } & 66.2 & 72.8 & 76.6 & 79.3 & 81.5 & 76.9 & 87.0 & 93.1 & 97.6 & 101.1 \\
\hline & $(59.2,73.1)$ & $(65,80.5)$ & $(68.4,84.8)$ & $(70.9,87.8)$ & $(72.7,90.2)$ & $(57.3,96.6)$ & $(61,113)$ & $(62.8,123.4)$ & $(63.9,131.2)$ & $(64.7,137.5)$ \\
\hline \multirow{2}{*}{ A6 } & 74.9 & 86.8 & 94.2 & 99.7 & 104.1 & 71.3 & 84.0 & 92.1 & 98.1 & 103.0 \\
\hline & $(59.9,89.8)$ & $(67.1,106.5)$ & $(71.1,117.3)$ & $(73.9,125.6)$ & $(76,132.2)$ & $(53.6,89)$ & $(59.8,108.2)$ & $(63.1,121)$ & $(65.3,130.9)$ & $(67,139.1)$ \\
\hline \multirow{2}{*}{ A7 } & 64.6 & 72.0 & 76.4 & 79.4 & 81.8 & 57.8 & 64.6 & 68.6 & 71.4 & 73.6 \\
\hline & $(57,72.2)$ & $(63.8,80.2)$ & $(67.8,85)$ & $(70.6,88.3)$ & $(72.8,90.9)$ & $(49.7,65.9)$ & $(55.9,73.2)$ & $(59.6,77.6)$ & $(62.1,80.6)$ & $(64.1,83)$ \\
\hline \multirow{2}{*}{ A8 } & 57.3 & 64.0 & 67.9 & 70.6 & 72.8 & 48.3 & 54.0 & 57.4 & 59.8 & 61.6 \\
\hline & $(49.6,65)$ & $(55.7,72.2)$ & $(59.2,76.5)$ & $(61.7,79.5)$ & $(63.7,81.9)$ & $(40,56.6)$ & $(45.2,62.8)$ & $(48.2,66.5)$ & $(50.3,69.2)$ & $(52,71.2)$ \\
\hline \multirow[b]{2}{*}{ B1 } & 44.9 & 50.2 & 53.3 & 55.5 & 57.2 & 51.1 & 60.8 & 67.0 & 71.7 & 75.5 \\
\hline & $(37.1,52.8)$ & $(41.8,58.6)$ & $(44.6,62)$ & $(46.5,64.4)$ & $(48,66.3)$ & $(37.1,65.1)$ & $(43,78.6)$ & $(46.4,87.7)$ & $(48.7,94.7)$ & $(50.4,100.6)$ \\
\hline \multirow[b]{2}{*}{ B2 } & 54.5 & 60.3 & 63.8 & 66.2 & 68.1 & 50.42 & 55.9 & 59.10 & 61.4 & 63.1 \\
\hline & $(47.6,61.3)$ & $(52.8,67.9)$ & $(55.8,71.7)$ & $(58,74.5)$ & $(59.7,76.6)$ & $(43.5,57.4)$ & $(48.2,63.6)$ & $(51,67.2)$ & $(53,69.8)$ & $(54.5,71.8)$ \\
\hline \multirow{2}{*}{ B3 } & 55.4 & 62.3 & 66.3 & 69.1 & 71.3 & 60.4 & 72.8 & 80.9 & 86.9 & 91.8 \\
\hline & $(46.1,64.7)$ & $(52.5,72)$ & $(56.3,76.3)$ & $(58.9,79.4)$ & $(60.9,81.7)$ & $(40.9,80)$ & $(48.3,97.4)$ & $(52.5,109.2)$ & $(55.4,118.4)$ & $(57.6,126.1)$ \\
\hline \multirow{2}{*}{ B4 } & 53.0 & 59.2 & 62.8 & 65.4 & 67.4 & 43.3 & 48.4 & 51.3 & 53.4 & 55.1 \\
\hline & $(45,60.9)$ & $(50.7,67.7)$ & $(54,71.7)$ & $(56.4,74.5)$ & $(58.2,76.7)$ & $(35.4,51.2)$ & $(39.9,56.8)$ & $(42.5,60.1)$ & $(44.4,62.5)$ & $(45.8,64.3)$ \\
\hline \multirow{2}{*}{ B5 } & 53.7 & 60.0 & 63.7 & 66.3 & 68.4 & 53.2 & 59.8 & 63.6 & 66.2 & 68.4 \\
\hline & $(45.9,61.6)$ & $(51.6,68.5)$ & $(55,72.5)$ & $(57.3,75.4)$ & $(59.2,77.6)$ & $(44.2,62.2)$ & $(50.3,69.3)$ & $(53.8,73.4)$ & $(56.2,76.3)$ & $(58.1,78.6)$ \\
\hline \multirow{2}{*}{ B6 } & 133.5 & 160.4 & 177.8 & 190.8 & 201.4 & 103.8 & 123.9 & 136.7 & 146.3 & 154.1 \\
\hline & $(101.3,165.8)$ & $(116.7,204.2)$ & $(125.7,229.8)$ & $(132.1,249.5)$ & $(137,265.8)$ & $(74.5,133.1)$ & $(83.5,164.2)$ & $(88.4,185)$ & $(91.6,201.1)$ & $(93.9,214.4)$ \\
\hline
\end{tabular}

\subsection{Maximum expected return value}

The rainfall return levels and their $95 \%$ confidence intervals are compared in Table 6 , and some relevant return levels and times are plotted in Fig. 6. The return level for nearly all stations was limited, except for Tortosa (B6) and Cabañas de Virtus (A1) in the first period, each at an opposite end of the basin. This behaviour can be considered normal for Tortosa because of its proximity to the Mediterranean Sea, and its return levels are slightly lower than those found by
Bodini and Cossu (2010) in Sardinia. For the second period, high values are maintained for Tortosa (B6), but two new rain gauges in the north central area of the basin appear with high, but not extreme, values.

Low values are presented by Logroño (B1) in the first period and Daroca (B4) and Embalse de Yesa (A3) in the second. The latter two are relevant because of the decrease of their return levels from the first to second periods, with Daroca (B4) showing a previous significant decay in daily maximum precipitation (MAX, Table 2). 
Table 7. Estimate return time (year) and their $95 \%$ confidence intervals for different rainfall levels $\left(\mathrm{mm} \mathrm{day}^{-1}\right)$.

\begin{tabular}{|c|c|c|c|c|c|c|c|c|c|c|c|c|}
\hline \multirow{2}{*}{ Gauge } & \multicolumn{6}{|c|}{ Level of rainfall $(\mathrm{mm})$ Period: 1957-1979 } & \multicolumn{6}{|c|}{ Level of rainfall $(\mathrm{mm})$ Period: 1980-2002 } \\
\hline & 40 & 50 & 60 & 70 & 100 & 150 & 40 & 50 & 60 & 70 & 100 & 150 \\
\hline \multirow{2}{*}{ A1 } & 0.3 & 0.6 & 1.1 & 2.1 & 11.0 & 114.7 & 0.8 & 2.5 & 7.2 & 21.2 & 532.9 & $>900$ \\
\hline & $(0.2,0)$ & $(0.4,1)$ & $(0.6,2)$ & $(0.8,3)$ & $(0.8,24)$ & $(0.8,364)$ & $(0.4,1)$ & $(1,4)$ & $(2,12)$ & $(3.2,39)$ & $(3.4,>900)$ & $(3.4,>900)$ \\
\hline \multirow{2}{*}{ A2 } & 0.8 & 2.3 & 6.8 & 19.6 & 475.9 & $>900$ & 0.9 & 2.7 & 8.1 & 24.1 & 628.5 & $>900$ \\
\hline & $(0.4,1)$ & $(1,4)$ & $(2.1,11)$ & $(3.8,35)$ & $(4.4,>900)$ & $(4.4,>900)$ & $(0.5,1)$ & $(1.1,4)$ & $(2.1,14)$ & $(3.2,45)$ & $(3.2,>900)$ & $(3.2,>900)$ \\
\hline \multirow{2}{*}{ A3 } & 1.5 & 3.8 & 8.8 & 19.0 & 136.7 & $>900$ & 18.4 & 125.8 & 860.6 & $>900$ & $>900$ & $>900$ \\
\hline & $(0.6,2)$ & $(1,7)$ & $(1,17)$ & $(1,40)$ & $(1,385)$ & $(1,>900)$ & $(0.1,43)$ & $(0.1,349)$ & $(0.1,2750)$ & $(0.1,>900)$ & $(0.1,>900)$ & $(0.1,>900)$ \\
\hline \multirow{2}{*}{ A4 } & 0.7 & 1.6 & 3.5 & 7.3 & 52.7 & 774.3 & 0.9 & 2.1 & 4.3 & 8.5 & 48.9 & 473.9 \\
\hline & $(0.4,1)$ & $(0.7,3)$ & $(1,6)$ & $(1,14)$ & $(1,139)$ & $(1,>900)$ & $(0.4,1)$ & $(0.7,3)$ & $(0.7,8)$ & $(0.7,18)$ & $(0.7,139)$ & $(0.7,1963)$ \\
\hline \multirow{2}{*}{ A5 } & 0.6 & 1.8 & 5.2 & 15.0 & 351.9 & $>900$ & 0.6 & 1.3 & 2.9 & 6.1 & 46.7 & 793.4 \\
\hline & $(0.4,1)$ & $(0.8,3)$ & $(1.8,9)$ & $(3.3,27)$ & $(4.3,755)$ & $(4.3,>900)$ & $(0.3,1)$ & $(0.5,2)$ & $(0.5,5)$ & $(0.5,13)$ & $(0.5,151)$ & $(0.5,>900)$ \\
\hline \multirow{2}{*}{ A6 } & 0.9 & 1.9 & 3.9 & 7.4 & 40.6 & 379.3 & 1.2 & 2.6 & 5.1 & 9.3 & 43.6 & 308.9 \\
\hline & $(0.4,1)$ & $(0.8,3)$ & $(1.2,7)$ & $(1.3,14)$ & $(1.3,95)$ & $(1.3,>900)$ & $(0.5,2)$ & $(0.8,4)$ & $(0.9,9)$ & $(0.9,19)$ & $(0.9,112)$ & $(0.9,>900)$ \\
\hline \multirow{2}{*}{ A7 } & 1.0 & 2.6 & 6.5 & 16.5 & 273.1 & $>900$ & 1.6 & 4.5 & 12.5 & 34.8 & 742.1 & $>900$ \\
\hline & $(0.5,2)$ & $(1,4)$ & $(2.1,11)$ & $(4.1,29)$ & $(9.1,547)$ & $(9.1,>900)$ & $(0.5,3)$ & $(1.1,8)$ & $(2,23)$ & $(2.5,67)$ & $(2.5,>900)$ & $(2.5,>900)$ \\
\hline \multirow[b]{2}{*}{ A8 } & 1.7 & 4.7 & 13.2 & 37.5 & 853.2 & $>900$ & 3.7 & 12.3 & 41.2 & 137.4 & $>900$ & $>900$ \\
\hline & $(0.6,3)$ & $(1.2,8)$ & $(2.3,24)$ & $(3,72)$ & $(3,>900)$ & $(3,>900)$ & $(0.3,7)$ & $(0.3,25)$ & $(0.3,88)$ & $(0.3,312)$ & $(0.3,>900)$ & $(0.3,>900)$ \\
\hline \multirow{2}{*}{ B1 } & 5.2 & 19.5 & 72.7 & 270.8 & $>900$ & $>900$ & 4.0 & 9.2 & 19.0 & 36.1 & 175.8 & $>900$ \\
\hline & $(0.2,10)$ & $(0.2,41)$ & $(0.2,163)$ & $(0.2,651)$ & $(0.2,>900)$ & $(0.2,>900)$ & $(0.2,8)$ & $(0.2,19)$ & $(0.2,42)$ & $(0.2,85)$ & $(0.2,506)$ & $(0.2,>900)$ \\
\hline \multirow{2}{*}{ B2 } & 1.8 & 5.9 & 19.2 & 62.3 & 2122.9 & $>900$ & 2.7 & 9.5 & 33.6 & 119.2 & $>900$ & $>900$ \\
\hline & $(0.7,3)$ & $(1.5,10)$ & $(2.3,36)$ & $(2.3,126)$ & $(2.3,5234)$ & $(2.3,>900)$ & $(0.7,5)$ & $(1.2,18)$ & $(1.2,69)$ & $(1.2,263)$ & $(1.2,>900)$ & $(1.2,>900)$ \\
\hline \multirow{2}{*}{ B3 } & 2.1 & 5.8 & 15.9 & 43.7 & 903.7 & $>900$ & 2.5 & 5.2 & 9.8 & 17.2 & 70.9 & 412.2 \\
\hline & $(0.3,4)$ & $(0.6,11)$ & $(0.6,31)$ & $(0.6,89)$ & $(0.6,>900)$ & $(0.6,>900)$ & $(0,5)$ & $(0,11)$ & $(0,21)$ & $(0,39)$ & $(0,186)$ & $(0,>900)$ \\
\hline \multirow{2}{*}{ B4 } & 2.4 & 7.2 & 21.9 & 66.5 & $>900$ & $>900$ & 6.3 & 25.0 & 98.2 & 386.5 & $>900$ & $>900$ \\
\hline & $(0.5,4)$ & $(1.1,13)$ & $(1.3,43)$ & $(1.3,137)$ & $(1.3,>900)$ & $(1.3,>900)$ & $(0.1,13)$ & $(0.1,55)$ & $(0.1,231)$ & $(0.1,979)$ & $(0.1,>900)$ & $(0.1,>900)$ \\
\hline \multirow{2}{*}{ B5 } & 2.2 & 6.6 & 19.9 & 59.8 & $>900$ & $>900$ & 2.4 & 7.1 & 20.5 & 59.5 & $>900$ & $>900$ \\
\hline & $(0.6,4)$ & $(1.1,12)$ & $(1.5,38)$ & $(1.5,121)$ & $(1.5,>900)$ & $(1.5,>900)$ & $(0.3,5)$ & $(0.5,14)$ & $(0.5,41)$ & $(0.5,125)$ & $(0.5,>900)$ & $(0.5,>900)$ \\
\hline \multirow{2}{*}{ B6 } & & 0.6 & 0.9 & 1.3 & 3.7 & 15.4 & 0.5 & 0.9 & 1.6 & 2.5 & 8.7 & 44.5 \\
\hline & $(0.2,1)$ & $(0.3,1)$ & $(0.4,1)$ & $(0.6,2)$ & $(1.2,6)$ & $(1.4,31)$ & $(0.2,1)$ & $(0.4,1)$ & $(0.6,3)$ & $(0.7,4)$ & $(0.8,18)$ & $(0.8,117)$ \\
\hline
\end{tabular}
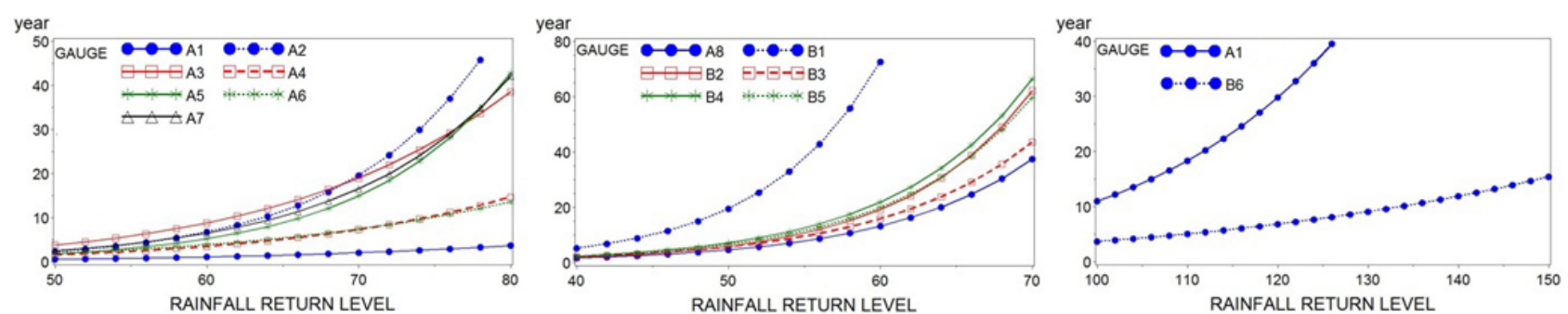

1957-1979 Period
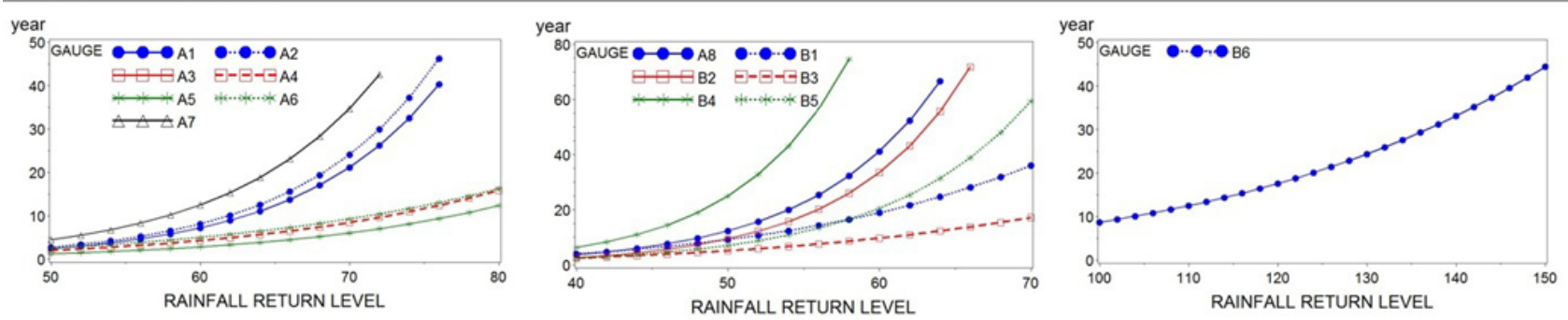

1980-2002 Period

Fig. 7. Return time (year) as function of maximum rainfall return level (mm day ${ }^{-1}$ ). Top plots are for the first period (1957-1979), and the bottom for the second period (1980-2002).

The differences between both periods show a significant decrease only for Cabañas de Virtus (A1) and Embalse de Yesa (A3) in the west and central Pyrenees (see Table 7); although Tortosa undergoes a greater absolute decrease (Fig. 6), it has no statistical significance. This means that greater uniformity is achieved in extreme rainfall in the north of the basin in the second period.
The return time patterns of the different rain gauges are similar, as expected. For most locations, daily rainfall events over $40 \mathrm{~mm}$ are produced more than once every three years. Table 7 shows the return times for the different return levels. We grouped those stations having a comparable return time for each period in Fig. 7. Tortosa (B6) shows the lowest values for any period, highlighting that its distribution function 
is significantly different from the rest of the stations. As expected, in the second period, there is an increase of the return times for almost all hydrographic stations, as exemplified by Cabañas de Virtus (A1).

\section{Conclusions}

Daily rainfall data from 1975 to 2002 from 14 stations located at different places in the Ebro River Basin and under different climatic conditions were used to study extreme rainfall trends in the area. Several statistical analyses were applied that mainly focused on the existence of trends in climatic rainfall indexes and the characterisation of the distribution of heavy rainfall.

For all cases, a direct relation among several rainfall climatic indexes (RF, Mean and the amount of rainfall caused by extremes values) for each station was found, with the sole exception of Tortosa. This station is in an area with a Mediterranean climate and is close to the sea, and it has a greater proportion of rainfall due to extreme values.

All extreme precipitation indexes show negative trends using the Yule-Walker method at an annual scale. However, only three of the indexes are statistically significant at the $5 \%$ level for some parameters, contrary to climate change model predictions, though confirming the results by Toreti et al. (2010) and Barrera et al. (2006) who also studied a Mediterranean area. The changing relationship occurred around the middle of the study period, and it can be compared to the NAO index.

The GPD successfully characterised the rainfall, estimating a threshold of $10 \mathrm{~mm}$. The GPD-scale parameter decreases in almost all gauges but is only statistically significant at the $95 \%$ level at two stations near the Pyrenees. However, whereas GPD shape parameter shows different tendencies, none of these tendencies show statistically significant differences. Therefore, there is a weakly significant reduction of the extreme values in the Ebro River Basin found at the areas with higher precipitation and likely near the Mediterranean Sea, but the results are not conclusive, as with other authors (Bodini and Cursso, 2010).

The return level for almost all stations was relatively low except for Tortosa. The differences between the first and second periods show a statistically significant decrease only for two rain gauges: Cabañas de Virtus (A1) and Embalse de Yesa (A3). Concerning the return time, it is noteworthy that for most locations, daily rainfall events over $40 \mathrm{~mm}$ are produced more than once every three years.

Acknowledgements. Funding provided by the Spanish Ministry of Science and Technology (MICINN) through project no. AGL201021501/AGR is greatly appreciated.

Edited by: A. Gobin

Reviewed by: three anonymous referees

\section{References}

Barrera, A., Llasat, M. C., and Barriendos, M.: Estimation of extreme flash flood evolution in Barcelona County from 1351 to 2005, Nat. Hazards Earth Syst. Sci., 6, 505-518, doi:10.5194/nhess-6-505-2006, 2006.

Bodini, A. and Cossu, Q. A.: Vulnerability assessment of CentralEast Sardinia (Italy) to extreme rainfall events, Nat. Hazards Earth Syst. Sci., 10, 61-72, doi:10.5194/nhess-10-61-2010, 2010.

Brunetti, M., Maugeri, M., Monti, F., and Nanni, T.: Changes in daily precipitation frequency and distribution in Italy over the last 120 years, J. Geophys. Res., 109, D05102, doi:10.1029/2003JD004296, 2004.

Bryan, E., Ringler, C., Okoba, B., Koo, J., Herrero, M., and Silvestri, S.: Agricultural Management for Climate Change Adaptation, Greenhouse Gas Mitigation, and Agricultural Productivity, International Food Police Research Institute (IFPRI) Discussion Paper 01098, Published by IFPRI, Washington, USA, 43 pp., 2011.

Cleveland, W. S.: The elements of graphing data, Wadsworth Advanced Books and Software, Monterey, California, 1985

Coles, S.: An Introduction to Statistical Modeling of Extreme Values, Springer Series in Statistics, London, 2001.

Cox, J. D.: Climate Crash: abrupt climate change and what it means for our future, Joseph Henry Press, Washington DC, 2005.

Gallego, M. C., García, J. A., Vaquero, J. M., and Mateos, V. L.: Changes in frequency and intensity of daily precipitation over the Iberian Peninsula, J. Geophys. Res., 111. D24105, doi:10.1029/2006JD007280, 2006.

Gonzalez-Hidalgo, J. C., Peña-Monné, J. L., and de Luis, M.: A review of daily soil erosion in Western Mediterranean areas, Catena, 71, 193-199, 2007.

Gonzalez-Hidalgo, J. C., Lopez-Bustins, J. A., Stepánek, P., MartinVide, J., and De Luis, M.: Monthly precipitation trends on the Mediterranean fringe of the Iberian Peninsula during the secondhalf of the twentieth century (1951-2000), Int. J. Climatol., 29, 1415-1429, 2009.

Groisman, P. Y., Knight, R. W., and Karl, T. R.: Heavy precipitation and high stremflow in the contiguous United States: trends in 20th century, B. Am. Meteorol. Soc., 82, 219-246, 2001.

Harvey, A. C.: The Econometric Analysis of Time Series, 2nd Edn., Cambridge, MIT Press, 1990.

Hollander, M. and Wolfe, D. A.: Nonparametric Statistical Methods, 2nd Edn., New York, John Wiley \& Sons, 1999.

Keeling, C. D.: The Carbon Dioxide Cycle, in: Chemistry of the Lower Atmosphere, edited by: Rasool, S., Plenum Press, New York, 251-329, 1973.

Killham, K.: Integrated soil management-moving towards globally sustainable agriculture, J. Agr. Sci., 149, 29-36, 2010.

Kim, B. S., Yoon, Y. H., and Lee H. D.: Analysis of Changes in Extreme Weather Events Using Extreme Indices, Eng. Res., 16, 175-183, 2011.

Lopez-Bustins, J. A., Martin-Vide, J., and Sanchez-Lorenzo, A.: Iberia winter rainfall trends based upon changes in teleconnection and circulation patterns, Global Planet. Change, 63, 171176, 2008.

Martin-Vide, J., Sanchez-Lorenzo, A., Lopez-Bustins, J. A., Cordobilla, M. J., Garcia-Manuel, A., and Raso, J. M.: Torrential rainfall in northeast of the Iberian Peninsula: synoptic patterns and 
WeMO influence, Adv. Sci. Res., 2, 99-105, doi:10.5194/asr-299-2008, 2008.

Milly, P. C. D., Wetherald, R. T., Dunne, K. A., and Delworth, T. L.: Increasing risk of great floods in a changing climate, Nature, 415, 514-517, 2002.

Müller, M., Kašpar, M., and Matschullat, J.: Heavy rains and extreme rainfall-runoff events in Central Europe from 1951 to 2002, Nat. Hazards Earth Syst. Sci., 9, 441-450, doi:10.5194/nhess-9-441-2009, 2009.

Oehlert G. W.: A Note on the Delta Method, The American Statistician, 46, 27-29, 1992.

O’Neal, M. R., Nearing, M. A., Vining, R. C., Southworth, J., and Pfeifer, R. A.: Climate change impacts on soil erosion in Midwest United States with changes in crop management, Catena, 61, 165-184, 2005.

Palmer, T. N. and Räisänen, J.: Quantifying the risk of extreme seasonal precipitation events in a changing climate, Nature, 415, 512-514, 2002.

Peterson, T. C., Folland, C., Gruza, G., Hogg, W., Mokssit, A., and Plummer, N.: Report on the Activities of the Working Group on Climate Change Detection and Related Rapporteurs 1998-2001, World Meteorological Organization, Geneva, Switzerland, ICPO Publication Series No. 48, 2001.

Pickands, J.: Statistical inference using extreme order statistics, Ann. Stat., 3, 119-131, 1975.

Räisänen, J., Hansson, U., Ullerstig, A., Döscher, R., Graham, L. P., Jones, C., Meier, H. E. M., Samuelsson, P., and Willén, U.: European climate in the late twenty-first century: regional simulations with two driving global models and two forcing scenarios, Clim. Dynam., 22, 13-31, 2004.
Ramos, M. C.: Rainfall distribution patterns and their change over time in a Mediterranean area, Theor. Appl. Climatol., 69, 163170, 2001.

Rodrigo, F. S.: Changes in the probability of extreme daily precipitation observed from 1951 to 2002 in the Iberian Peninsula, Int. J. Climatol., 30, 1512-1525, 2010.

Rodríguez, R., Llasat, M. C., and Wheeler, D.: Analysis of the Barcelona precipitation series 1850-1991, Int. J. Climatol., 19, 787-801, 1999.

Tarquis, A. M., Gobin, A., and Semenov, M.: Preface: Agriculture in a changing climate, Clim. Res., 44, 1-2, 2010.

Toreti, A., Xoplaki, E., Maraun, D., Kuglitsch, F. G., Wanner, H., and Luterbacher, J.: Characterisation of extreme winter precipitation in Mediterranean coastal sites and associated anomalous atmospheric circulation patterns, Nat. Hazards Earth Syst. Sci., 10, 1037-1050, doi:10.5194/nhess-10-1037-2010, 2010.

Valencia, J. L.: Estudio estadístico de la calidad de las aguas de la cuenca hidrográfica del río Ebro, PhD Thesis, Universidad Politécnica de Madrid, Spain, 2007.

Valencia, J. L., Saa, A., Gascó, J. M., and Tarquis, A. M.: A Universal Multifractal description applied to precipitation patterns in the Ebro River Basin, Spain, Clim. Res., 44, 17-25, 2010.

Wang, C.: Atlantic Climate Variability and Its Associated Atmospheric Circulation Cells, J. Climate, 15, 1516-1536, 2002.

Zurbenko, I., Porter, P. S., Gui, R., Rao, S. T., Ku, J. Y., and Eskridge, R. E.: Detecting Discontinuities in Time Series of UpperAir Data: Development and Demonstration of an Adaptive Filter Technique, J. Climate, 9, 3548-3560, 1996. 